\title{
Raxibacumab augments hemodynamic support and improves outcomes during shock with $B$. anthracis edema toxin alone or together with lethal toxin in canines
}

Kenneth E Remy ${ }^{1 *}$, Xizhong Cui ${ }^{1}$, Yan Li ${ }^{1}$, Junfeng Sun ${ }^{1}$, Steven B Solomon ${ }^{1}$, Yvonne Fitz $^{1}$, Amisha V Barochia ${ }^{2}$, Mariam Al-Hamad', Mahtab Moayeri ${ }^{3}$, Stephen L Leppla $^{3}$ and Peter Q Eichacker ${ }^{1}$

\author{
* Correspondence: \\ kenneth.remy@mail.nih.gov \\ ${ }^{1}$ Critical Care Medicine Department, \\ Clinical Center, National Institutes of \\ Health, Bldg 10, Rm 2C145, \\ Bethesda, MD 20892, USA \\ Full list of author information is \\ available at the end of the article
}

\begin{abstract}
Background: Lethal and edema toxin contribute to shock and lethality with Bacillus anthracis. We showed previously in a 96-h sedated canine model that raxibacumab, a monoclonal antibody against protective antigen, augmented hemodynamic support (HS) and improved survival with lethal toxin challenge. Here we study raxibacumab further. Using this model, we have now studied raxibacumab with $24 \mathrm{~h}$ edema toxin challenges (Study 1), and lethal and edema toxin challenges together (Study 2).

Methods: Using our canine model, we have now studied raxibacumab with $24 \mathrm{~h}$ edema toxin challenges (Study-1), and lethal and edema toxin challenges together (Study-2).

Results: In Study 1, compared to no treatment, HS (titrated fluid and norepinephrine) increased mean arterial blood pressure (MAP, $p \leq 0.05)$ but not survival [0 of $10(0 / 10)$ animals survived in each group] or median survival time [43.8 h (range 16.8 to 80.3 ) vs. $45.2 \mathrm{~h}$ (21.0 to 57.1)]. Compared to HS, HS with raxibacumab treatment at or $6 \mathrm{~h}$ after the beginning of edema toxin increased MAP and survival rate (6/7 and 7/8, respectively) and time [96.0 h (39.5 to 96.0) and $96.0 \mathrm{~h}$ (89.5 to 96.0), respectively]; $(p \leq 0.05)$. HS with raxibacumab at $12 \mathrm{~h}$ increased MAP $(p \leq 0.05)$ but not survival [1/5; $55.3 \mathrm{~h}$ (12.6 to 96.0)]. In Study-2, survival rate and time increased with HS and raxibacumab at $0 \mathrm{~h}(4 / 4)$ or $6 \mathrm{~h}$ after (3/3) beginning lethal and edema toxin compared to HS [0/5; $71.5 \mathrm{~h}$ (65 to 93)] ( $p=0.01$ averaged over raxibacumab groups).
\end{abstract}

Conclusions: Raxibacumab augments HS and improves survival during shock with lethal and edema toxin.

Keywords: B. anthracis; Edema toxin; Lethal toxin; Monoclonal antibody; Protective antigen; Raxibacumab

\section{Springer}

\section{Background}

During recent outbreaks of Bacillus anthracis infection in developed countries, mortality rates in patients with shock have been close to $80 \%$ [1-4]. By comparison, mortality from shock due to other types of bacterial infection is reported to be 20 to $50 \%$ [5-8]. Adjunctive therapies that augment conventional hemodynamic support (HS) during B. anthracis shock may improve outcomes from this lethal infection.

(c) 2015 Remy et al.; licensee Springer. This is an Open Access article distributed under the terms of the Creative Commons Attribution License (http://creativecommons.org/licenses/by/4.0), which permits unrestricted use, distribution, and reproduction in any medium, provided the original work is properly credited. 
B. anthracis produces two binary exotoxins, lethal (LT) and edema toxins (ET) [9-11], each consisting of a toxic moiety [lethal factor (LF) and edema factor (EF), respectively] and protective antigen (PA), which mediates transport of the toxic moieties into host cells. Lethal factor is a metalloprotease that blocks mitogen-activated protein kinase kinases and stimulates inflammasome formation [4,12,13]. Edema factor is a calmodulin-dependent adenylyl cyclase that increases intracellular cAMP levels [14-17]. Although on a weight basis LT is five to ten times more lethal than ET, both toxins are thought to contribute to shock during infection with B. anthracis [18-20].

We previously developed a $96 \mathrm{~h}$ sedated, instrumented, and ventilated canine model of B. anthracis toxin-associated shock in which LT or ET was infused over $24 \mathrm{~h}$ to simulate release during infection [18]. In this model, lethal doses of the two toxins had very different hemodynamic effects. While both caused hypotension that persisted for $96 \mathrm{~h}$, LT produced myocardial dysfunction while ET produced marked arterial dilation. In this model, a non-lethal dose of ET augmented the lethal effects of LT [18].

We subsequently employed this model to investigate the treatment with hemodynamic support (titrated normal saline and norepinephrine infusions, HS) alone or together with raxibacumab (raxi), a PA-directed monoclonal antibody (originally Human Genome Sciences and now GlaxoSmithKline, Rockville, MD, USA) for LT-associated shock [21]. By targeting PA in the extracellular space, raxi inhibits the two toxins by blocking host cell internalization of the toxic moieties LF and EF, which is necessary for toxin activity [22-25]. Hemodynamic support alone produced a small but significant increase in survival [21]. However, compared to HS alone, HS with raxi administered either at the start of LT or 9 or $12 \mathrm{~h}$ later, promoted fluid mobilization, increased blood pressure, reduced vasopressor requirements, and improved myocardial function and survival [21]. Since raxi has now been added to the Strategic National Stockpile but has not been tested clinically during $B$. anthracis-associated shock, we employed this canine model to also investigate the effects of HS alone or together with raxi for shock caused by lethal ET challenge in one study (Study-1) and lethal challenge with LT combined with a similar weight dose of ET in another study (Study-2). We hypothesized that HS with raxi would improve survival and hemodynamics compared to HS in shock from ET alone or LT and ET together.

\section{Methods}

Study design

The National Institutes of Health Clinical Center Animal Care and Use Committee approved these studies as protocol CCM1201. Four purpose-bred beagles (weighing 10 to $12 \mathrm{~kg}$ ) prepared as previously described with tracheostomy tubes and venous, pulmonary and systemic arterial, and urinary catheters, were studied weekly [18]. Sedation, maintenance fluids, and mechanical ventilation were applied similarly to all groups using standardized ICU protocols [21,26].

In Study 1, starting at $0 \mathrm{~h}$ (T0), all animals were challenged with a $24 \mathrm{~h}$ ET infusion (Figure S1A in Additional file 1). Ten weekly experiments were conducted. Each week, in the first six experiments, four animals were randomized at the start of ET infusion to: no treatment (fixed maintenance fluid only), hemodynamic support alone (HS, fluid and norepinephrine titrated to pulmonary, and systemic arterial pressures, respectively), or HS combined with a single dose of raxi administered either at the start of ET (HS + mAbT0) or $12 \mathrm{~h}$ later (HS+ mAbT12) (Figure 1A). Based on the results of these six 


\begin{tabular}{|cccccc}
\hline \multirow{2}{*}{ A Individual Survival Times (h) } \\
\hline \multirow{2}{*}{ Experiment } & \multicolumn{5}{c}{ Treatment Groups } \\
\cline { 2 - 6 } & No Treatment & HS & HS+mAbT0 & HS+mAbT6 & HS+mAbT12 \\
\hline 1 & 21 & 16.8 & 96 & - & 66.5 \\
2 & 37.8 & 40.5 & 96 & - & 12.6 \\
3 & 23.7 & 38.8 & $39.5,96$ & - & - \\
4 & 34.6 & 50.5 & 96 & - & 96 \\
5 & 43.3 & 33.3 & 96 & - & 48 \\
6 & 55 & 26 & 96 & - & 55.3 \\
7 & 50 & 80.3 & - & 96,96 & - \\
8 & 57.1 & 47 & - & $96,89.5$ & - \\
9 & 56.6 & 50.3 & - & 96,96 & - \\
10 & 47 & 71 & - & 96,96 & - \\
\hline
\end{tabular}

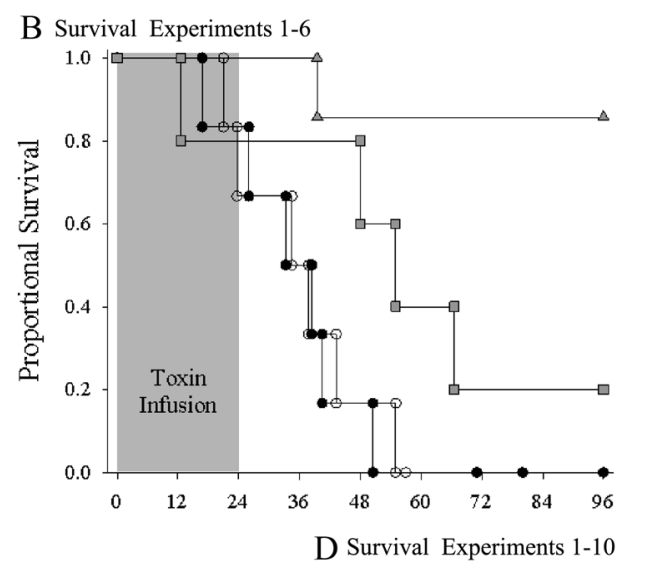

C Survival Experiments 7-10
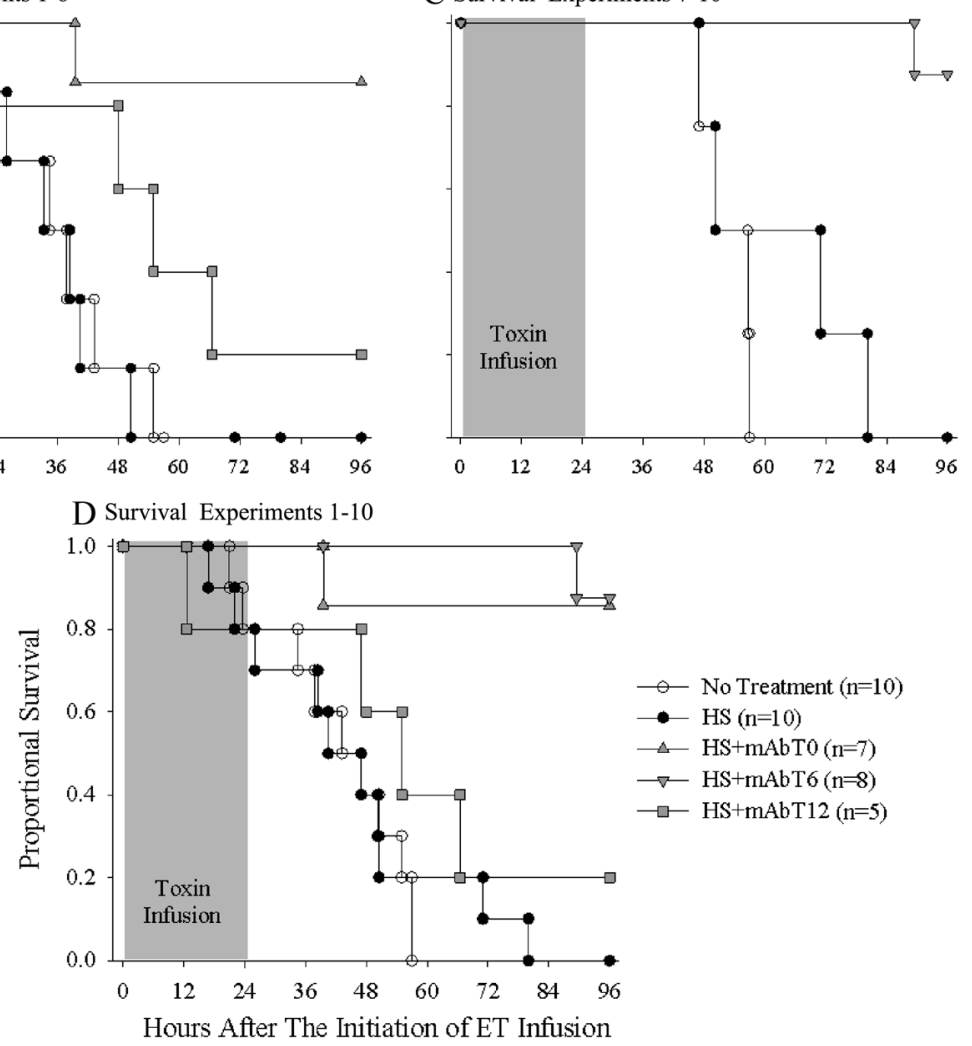

Figure 1 Survival Times and the proportion of animals surviving over time. This figure shows the individual survival times for each of the animals assigned to no treatment (maintenance fluid only),

hemodynamic support alone (HS; fluids and norepinephrine titrated to pulmonary artery wedge pressure and mean arterial blood pressure, respectively), or HS combined with raxibacumab administered at the start of (HS + mAbT0) or $6 \mathrm{~h}(\mathrm{HS}+\mathrm{mAbT6})$ or $12 \mathrm{~h}(\mathrm{HS}+\mathrm{mAbT12})$ after the start of edema toxin (ET) infusion in each of the ten weekly experiments comprising Study 1 (A) (see Methods). This figure also shows the proportion of animals surviving over time in experiments 1 to 6 (B), 7 to 10 (C), and for all ten experiments together (D). In experiment 3 , an animal randomized to receive $\mathrm{HS}+\mathrm{mAbT12}$ received $\mathrm{HS}+$ mAbT0 instead.

experiments (see Results), in the subsequent four experiments, each week four animals were randomized to no treatment $(n=1)$, HS alone $(n=1)$, or HS combined with raxi administered $6 \mathrm{~h}$ after the start of ET (HS + mAbT6) $(n=2)$.

In Study 2, four animals were challenged weekly with a lethal dose of LT combined with a similar weight dose of ET administered as $24 \mathrm{~h}$ infusions (Figure S1B in 
Additional file 1). Comparable doses of LT and ET together had previously additive effects on lethality compared to LT alone [18]. At the start of toxin infusion, animals were randomized to receive $\mathrm{HS}$ alone or HS combined with raxi administered at $0 \mathrm{~h}$ $(\mathrm{HS}+\mathrm{mAbT} 0)$ or $6 \mathrm{~h}(\mathrm{HS}+\mathrm{mAbT} 6)$. As described in the results, after completion of three experiments, this study was concluded and data were analyzed.

Hemodynamic monitoring was started at $0 \mathrm{~h}$ and continued until the end of both Studies 1 and 2 (Figure S1A and B in Additional file 1). Cardiopulmonary and other laboratory measures were obtained immediately before and at regular intervals after initiation of toxin. Whereas blood pressure, heart rate (HR), temperature, and oxygen saturation were continuously monitored, central venous pressure (CVP) was recorded every $2 \mathrm{~h}$, and pulmonary capillary wedge pressure (PCWP) was measured every $2 \mathrm{~h}$ for the first $8 \mathrm{~h}$, and every $4 \mathrm{~h}$ thereafter. Arterial blood gases (ABGs) were obtained every $2 \mathrm{~h}$ for the first $8 \mathrm{~h}$ and every $8 \mathrm{~h}$ or as needed based on protocol thereafter. Left ventricular ejection fraction (LVEF), measured by echocardiography, and chemistry and complete blood count data were obtained at $24 \mathrm{~h}$ intervals. Total fluid intake was recorded every $2 \mathrm{~h}$, whereas urine output was recorded every $24 \mathrm{~h}$ and at time of death. Norepinephrine requirements were recorded hourly. Surviving animals were euthanized at $96 \mathrm{~h}$ after measurements were completed.

\section{Toxin and treatments}

Lethal and edema toxins were prepared as previously described and administered in doses designed to produce lethality rates greater than 75\% [18]. In Study 1, the ET challenge consisted of PA, $410 \mu \mathrm{g} / \mathrm{kg}$, and EF, $205 \mu \mathrm{g} / \mathrm{kg}$; while in Study 2, LT and ET challenge together consisted of PA, $10 \mu \mathrm{g} / \mathrm{kg}$, LF, $10 \mu \mathrm{g} / \mathrm{kg}$, and EF, $10 \mu \mathrm{g} / \mathrm{kg}$. The raxi dose employed in both studies (ten times the molar amount of PA administered to each animal) was administered as a single dose, $2 \mathrm{~mL}$ intravenous injection at the specified times (Figure S1 in Additional file 1). Animals not assigned to raxi treatment concurrently received a similar volume of a human inactive, non-specific iso-matched IgG1 monoclonal antibody (mAb CAT002 lot number: AG-193-73-M4L originally Human Genome Sciences and now GlaxoSmithKline, Rockville, MD, USA) which had been used in our previous study [21].

To ensure that animals studied had similar starting preload; at baseline, all animals had one to three boluses $(20 \mathrm{~mL} / \mathrm{kg})$ of normal saline as needed until a PCWP of $\geq 10 \mathrm{mmHg}$ was achieved. Thereafter, animals receiving HS were administered a single bolus of $20 \mathrm{~mL} / \mathrm{kg}$ normal saline if the PCWP (note times above) was found to be $<10 \mathrm{mmHg}$. Additionally, if at any time, the mean arterial blood pressure (MAP) decreased to $<80 \mathrm{mmHg}$ for $>5 \mathrm{~min}$, norepinephrine infusion was initiated at $0.2 \mu \mathrm{g} / \mathrm{kg} /$ min and, if necessary, increased in a stepwise fashion to $0.6,1$, or a maximum of $2 \mu \mathrm{g} /$ $\mathrm{kg} / \mathrm{min}$, every 5 minutes (and similarly titrated down if MAP was $>100 \mathrm{mmHg}$ for $>5 \mathrm{~min}$ ). Animals in the no treatment group in Study 1 had measures performed but did not receive titrated fluid or norepinephrine. Technicians blinded to raxi allocation administered all supportive therapies.

Ventilator management, temperature control, and sedation with midazolam, fentanyl, and medetomidine were managed uniformly for all groups based on previously reported protocols [26]. Stepwise ventilator adjustments were made to $\mathrm{FiO}_{2}$, positive endexpiratory pressure, and respiratory rate based on continuous pulse oximetry and 
regularly performed arterial blood gases. All animals received maintenance fluids (Normosol-M at $3 \mathrm{~mL} / \mathrm{kg} / \mathrm{h}$ for the first $36 \mathrm{~h}, 2 \mathrm{~mL} / \mathrm{kg} / \mathrm{h}$ for the next $36 \mathrm{~h}$, and then $1 \mathrm{~mL} / \mathrm{kg} / \mathrm{h}$ until study completion) [26]. Additional care for all animals included pharmacologic prophylaxis for gastrointestinal stress ulcers (famotidine) and deep venous thrombosis (heparin subcutaneously) and ceftriaxone to prevent catheter-related infections [26].

\section{Statistical methods}

Survival times between the two treatment groups were compared using exact log-rank tests (StatXact, Cytel Software Corp., Cambridge, MA). For all other variables, the change-from-baseline values for individual animals were compared unless there was no baseline value collected. To evaluate shock reversal, we standardized MAP and norepinephrine using Z-scores and then calculated a 'shock reversal' score (designated shock index) based on the difference of the MAP Z-score and norepinephrine Z-score, with a higher score indicating improved hemodynamics. Linear mixed models (SAS PROC Mixed, SAS version 9.3, Cary, NC) were used to compare the change from baseline values of different treatments for each time point. All animals were analyzed in the model, and the correlation of animals within each week was accounted for in the model as a random effect. Standard residual diagnostics were used to check model assumptions. Two-sided $p$ values of 0.05 or less were considered significant without adjusting for multiple comparisons.

\section{Results}

Study 1: Effect of hemodynamic support alone or together with PA-mAb during challenge with edema toxin

Survival

A total of 40 animals were challenged with $24 \mathrm{~h}$ ET infusions in ten weekly experiments (four animals per experiment). Over these experiments, all ten animals receiving no treatment (maintenance fluid only) and all ten animals receiving HS alone (see Methods) died with median survival times (ranges) of $45.2 \mathrm{~h}$ (21.0 to 57.1) and $43.8 \mathrm{~h}$ (16.8 to 80.3$)$, respectively $(p=0.61)$ (Figure 1$)$. In experiments 1 to 6 , six of seven animals receiving $\mathrm{HS}$ and raxi administered at $0 \mathrm{~h}(\mathrm{HS}+\mathrm{mAbT} 0)$ survived while only one of five animals receiving HS and raxi administered at $12 \mathrm{~h}$ (HS + mAbT12) survived, with the median survival times of $96.0 \mathrm{~h}$ (39.5 to 96.0) and $55.3 \mathrm{~h}$ (12.6 to 96.0), respectively. Compared to HS alone in experiments 1 to $6, \mathrm{HS}+\mathrm{mAbT0}$ improved survival significantly $(p=0.02)$ but HS + mAbT12 did not $(p=0.19)$. To conserve animals but still explore the potential benefit of delayed raxi treatment $(<12 \mathrm{~h}$ after toxin infusion), in experiments 7 to 10 , animals were randomized each week to no treatment $(n=1)$, HS alone $(n=1)$, or HS with raxi administered $6 \mathrm{~h}$ after the start of ET (HS + mAbT6, $n=2)$. In these experiments, seven of eight animals receiving HS + mAbT6 survived with a median survival time of $96.0 \mathrm{~h}$ (89.5 to 96.0), and this was significantly better than HS alone $(p=0.01)$.

\section{Other laboratory data}

Since few animals receiving no treatment or HS alone were alive for comparison after $48 \mathrm{~h}$ from Study 1 (Figure 1), analysis was conducted over the initial $48 \mathrm{~h}$ as lethality developed. To first determine whether there was any evidence of benefit with HS alone, 
this group was compared to the no treatment group (Figure 2). Then, the effects of HS with raxi administered at each of the three treatment times were compared to HS alone (Figures 3, 4, and 5).

Compared to no treatment, HS animals had increased fluid intake at 24 and $48 \mathrm{~h}$ and increased fluid (urine) output at $24 \mathrm{~h}$ (all $p \leq 0.05$ ), but no significant difference in net fluid balance (Figure 2). Norepinephrine was administered to HS animals by $6 \mathrm{~h}$ and then increased to the maximum level by $24 \mathrm{~h}$ where it remained until death in all

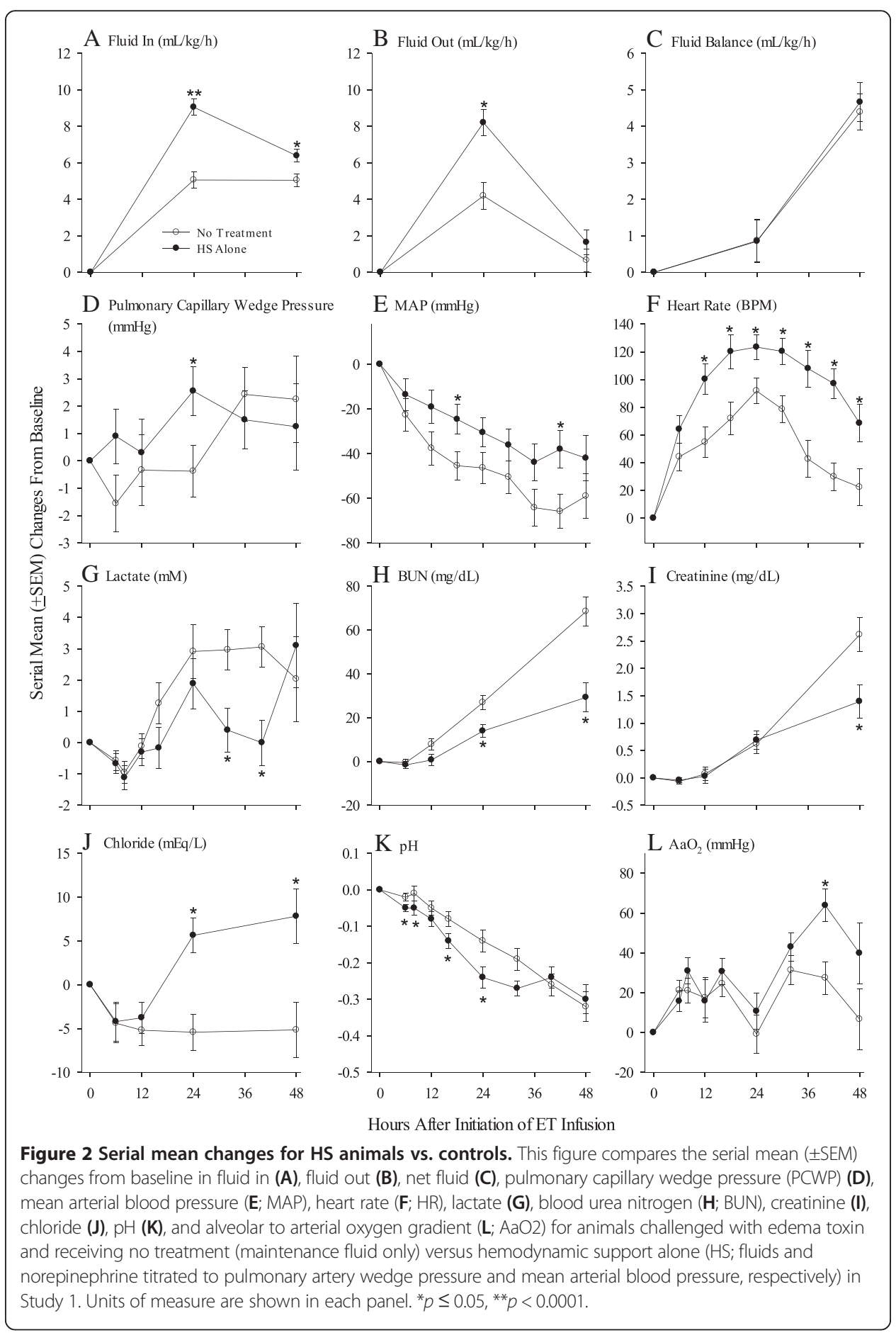




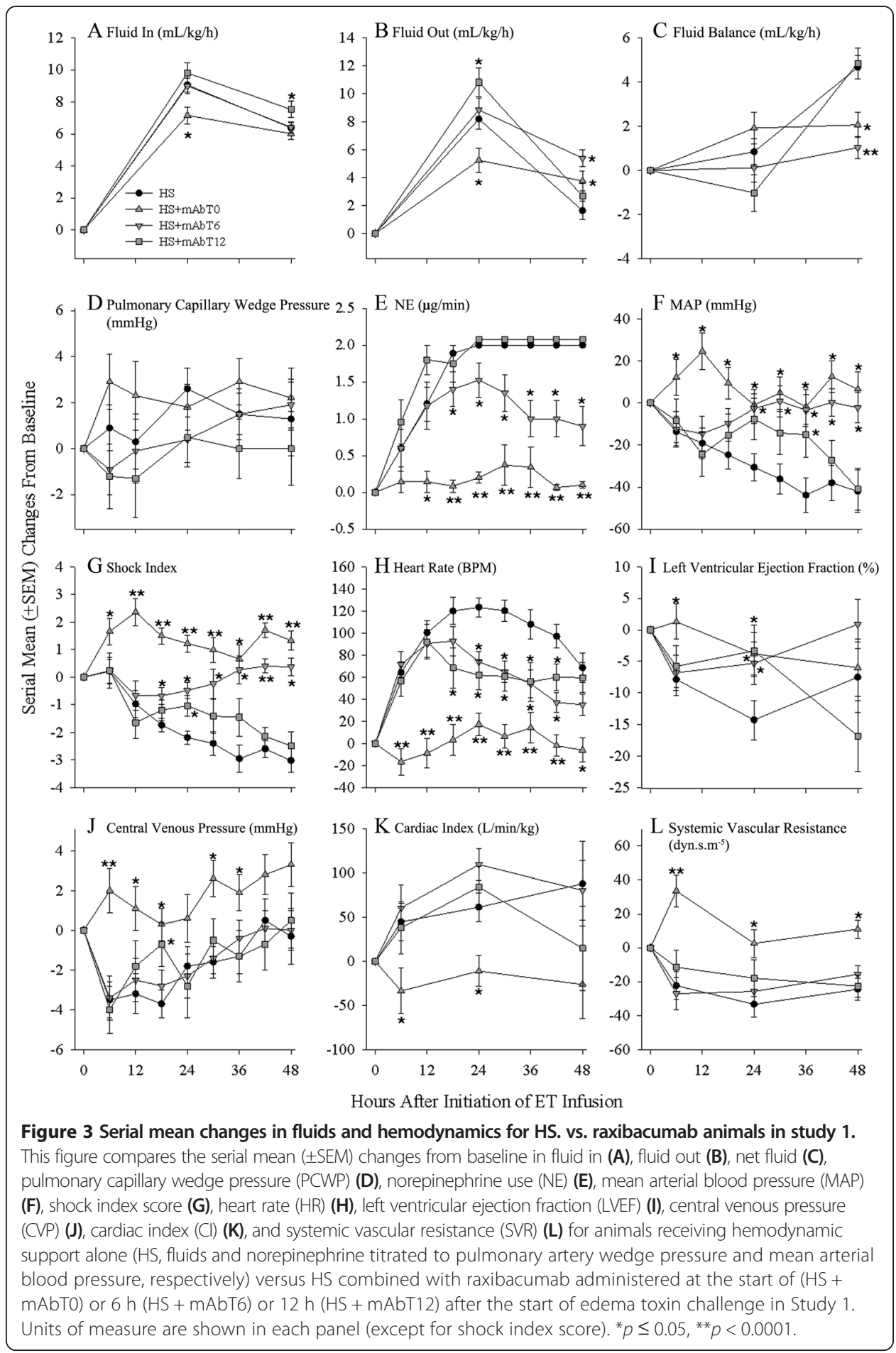

animals. Compared to no treatment, HS significantly increased PCWP at $24 \mathrm{~h}$, MAP at 18,30 , and $42 \mathrm{~h}$, and (possibly related to the maximum norepinephrine dose HS animals received) HR at 12 to $48 \mathrm{~h}(p \leq 0.05)$ (Figure 2). Consistent with treatment and improved hemodynamics, HS decreased lactate at 32 and $40 \mathrm{~h}$, blood urea nitrogen (BUN) levels at 24 and $48 \mathrm{~h}$, and creatinine $(\mathrm{Cr})$ at $48 \mathrm{~h}$. HS also increased chloride $\left(\mathrm{Cl}^{-}\right)$at 24 and $48 \mathrm{~h}$ and sodium $\left(\mathrm{Na}^{+}\right)$at $24 \mathrm{~h}\left(p \leq 0.05\right.$, data for $\mathrm{Na}^{+}$not shown). 


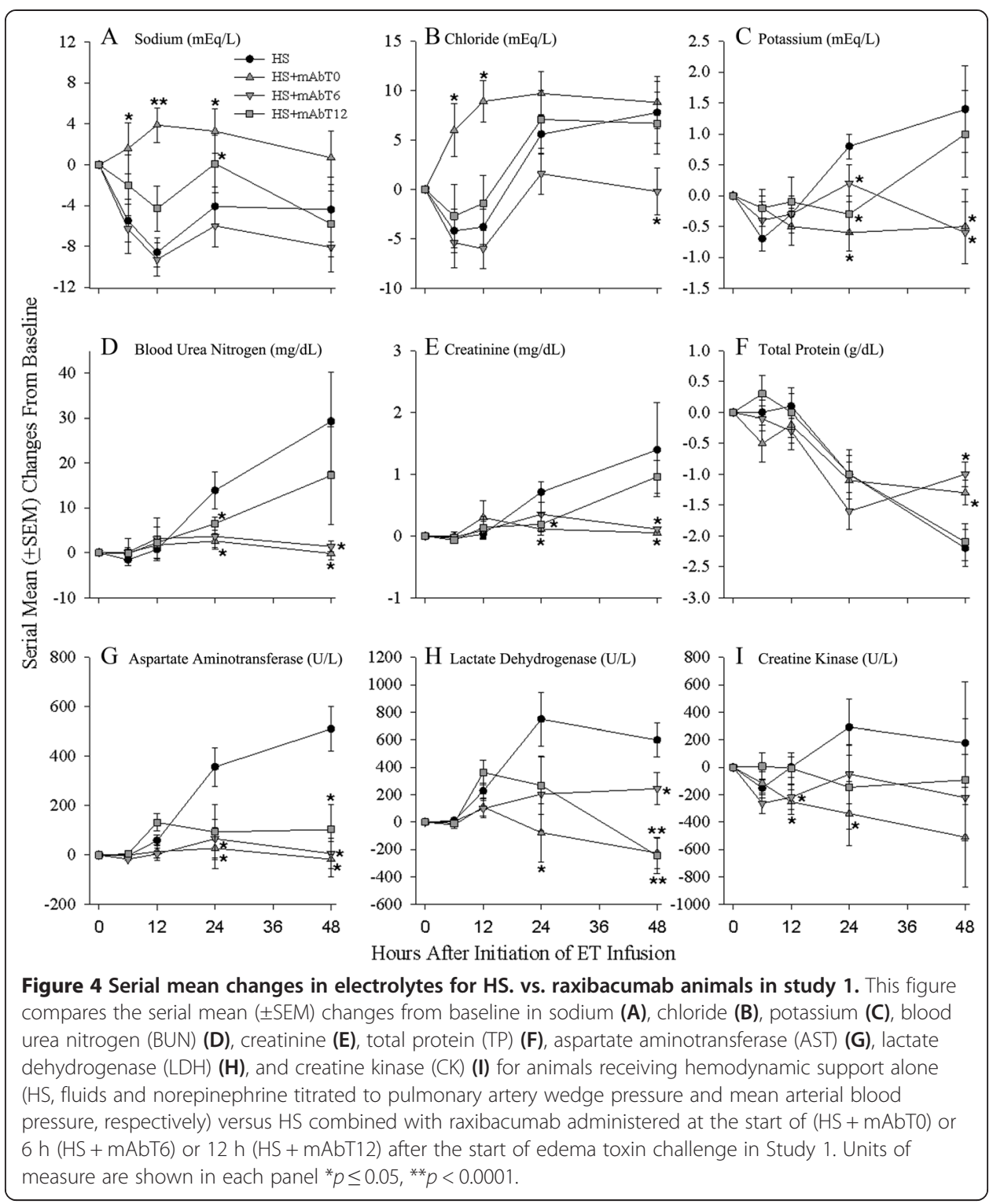

Despite decreases in lactate, HS decreased arterial base excess (ABE) levels at 6 to $24 \mathrm{~h}$, $\mathrm{pH}$ at 6 to $24 \mathrm{~h}$ (except $12 \mathrm{~h}$ ), and bicarbonate $\left(\mathrm{HCO}^{-}\right)$at 8 to $16 \mathrm{~h}$, possibly due to the normal saline administered ( $p \leq 0.05, \mathrm{ABE}$ and $\mathrm{HCO}^{-}$not shown). Notably, HS significantly decreased arterial oxygen $\left(\mathrm{PaO}_{2}\right)$ and increased alveolar to arterial oxygen gradient $\left(\mathrm{AaO}_{2}\right)$ at $40 \mathrm{~h}\left(p \leq 0.05\right.$, data for $\mathrm{PaO}_{2}$ not shown). As shown in Figure 2, the significant effects of HS on MAP, lactate, BUN, and Cr resulted in changes closer to baseline values than in controls not receiving treatment.

We next compared the effect of HS combined with raxi versus HS alone (Figures 3, 4, and 5). Since HS + mAbT0 and HS + mAbT6 both significantly increased survival compared to HS, while HS + mAbT12 did not, data are first presented for the two earlier raxi treatment groups. Compared to HS alone, HS + mAbT0 and HS + mAbT6 increased fluid (urine) output and net negative fluid balances at $48 \mathrm{~h}(p \leq 0.05)$ (Figure 3). Pulmonary capillary wedge pressure did not differ significantly between groups. Treatment with $\mathrm{HS}+\mathrm{mAbT0}$ and $\mathrm{HS}+\mathrm{mAbT} 6$ decreased norepinephrine requirement, 


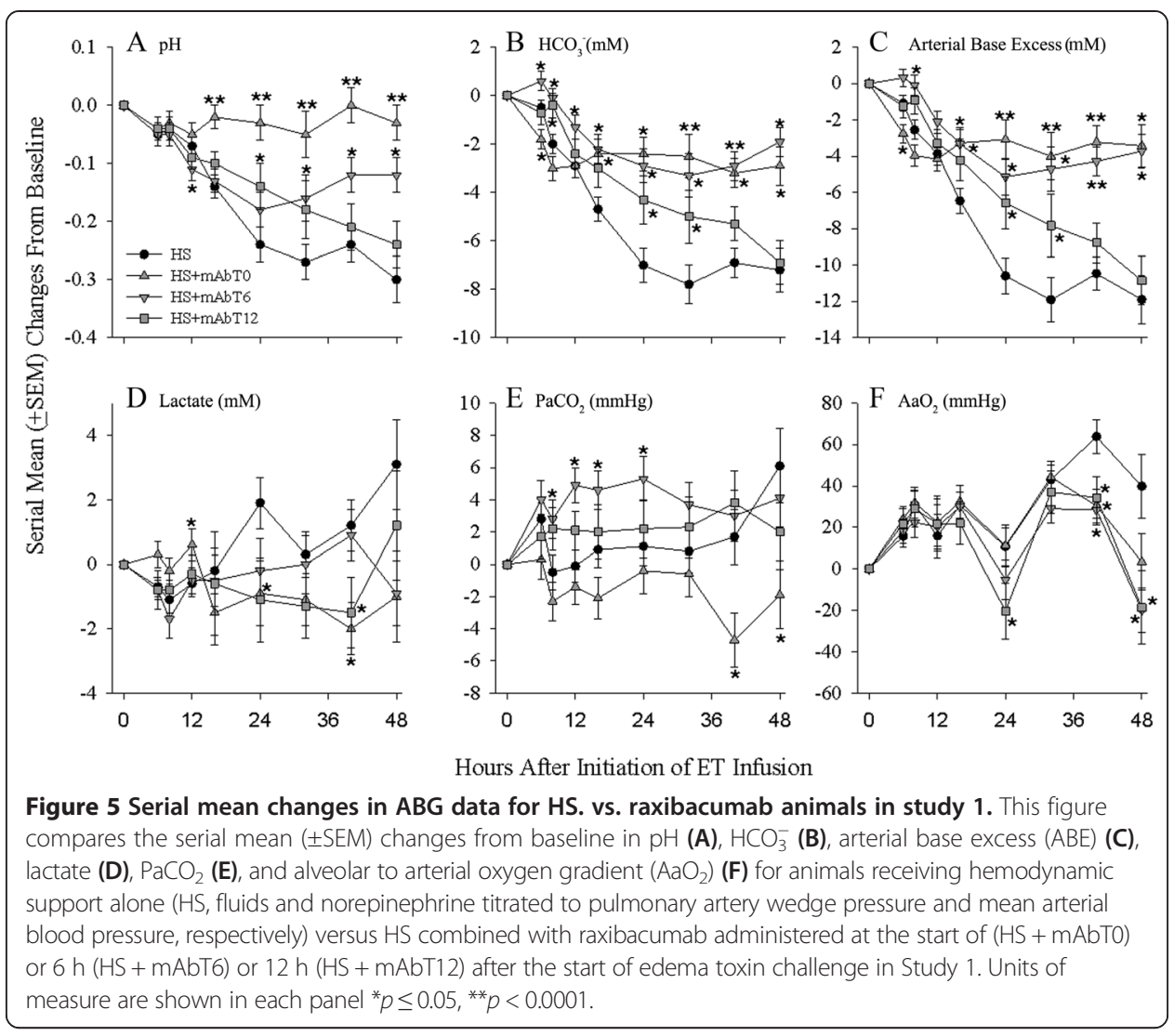

increased MAP and shock index scores, and decreased HR at multiple time points between 12 and $48 \mathrm{~h}(p \leq 0.05)$, although these effects occurred earlier and were more pronounced with HS + mAbT0. Both HS + mAbT0 and HS + mAbT6 increased left ventricular ejection fraction (LVEF) at $24 \mathrm{~h}$, total protein and albumin at $48 \mathrm{~h}$, and decreased $\mathrm{BUN}, \mathrm{Cr}$, potassium $\left(\mathrm{K}^{+}\right)$, aspartate amino-transaminase (AST), and lactate dehydrogenase (LDH) at 24 and/or $48 \mathrm{~h}$ and creatine kinase (CK) at $12 \mathrm{~h}(p \leq 0.05$ for all) (Figures 3 and 4, data for albumin not shown). While HS + mAbT0 and HS + mAbT6 had variable effects early on $\mathrm{ABE}, \mathrm{pH}$, and $\mathrm{HCO}^{-}$, both increased these significantly at multiple time points from 12 to $48 \mathrm{~h}(p \leq 0.05)$ (Figure 5). Both treatments also increased $\mathrm{PaO}_{2}$ and decreased $\mathrm{AaO}_{2}$ at either 40 or $48 \mathrm{~h}\left(p \leq 0.05\right.$, data for $\mathrm{PaO}_{2}$ not shown). Compared to HS alone, HS + mAbT0 also decreased fluid intake and output at $24 \mathrm{~h}$, increased CVP from 6 to $18 \mathrm{~h}$ and 30 to $36 \mathrm{~h}$, decreased cardiac index (CI) and increased systemic vascular resistance (SVR) from 6 to 24 or $48 \mathrm{~h}$, increased $\mathrm{Na}^{+}$ at 6 to $24 \mathrm{~h}$ and $\mathrm{Cl}^{-}$at 6 to $12 \mathrm{~h}$, decreased arterial carbon dioxide $\left(\mathrm{PaCO}_{2}\right)$ at 40 to $48 \mathrm{~h}$ and first increased lactate at $12 \mathrm{~h}$ and then decreased it at 24 and $40 \mathrm{~h}(p \leq 0.05)$. Compared to $\mathrm{HS}$ alone, $\mathrm{HS}+$ mAbT6 decreased $\mathrm{Cl}^{-}$at $48 \mathrm{~h}$ and increased $\mathrm{PaCO}_{2}$ at 8 to $24 \mathrm{~h}$.

Compared to HS alone, HS + mAbT12 increased fluid intake at $48 \mathrm{~h}$ and output at $24 \mathrm{~h}$ (both $p \leq 0.05$ ), but did not alter net fluid balance. Animals receiving $\mathrm{HS}+$ mAbT12 required increasing doses of norepinephrine just like HS alone animals and had modest increases in MAP (significant at $36 \mathrm{~h}, p=0.05$ ), although shock index scores did not differ significantly. Moreover, HS + mAbT12 treatment was associated 
with decreased $\mathrm{HR}$ at 18 to $42 \mathrm{~h}$, increased $\mathrm{HCO}^{-}$at 8,24 , and $32 \mathrm{~h}$ and $\mathrm{ABE}$ at 24 and $32 \mathrm{~h}$, increased $\mathrm{PaO}_{2}$ at $48 \mathrm{~h}$ and decreased $\mathrm{AaO}_{2}$ at 24, 40, and $48 \mathrm{~h}$ (all $p \leq 0.05$, data for $\mathrm{PaO}_{2}$ not shown).

As shown in Figures 3, 4, and 5, the effects of either HS + mAbT0, HS + mAbT6, or $\mathrm{HS}+\mathrm{mAbT} 12$ that were significant on norepinephrine requirements, MAP, Shock Index, HR, LVEF, CVP, CI, SVR, $\mathrm{Na}^{+}, \mathrm{K}^{+}, \mathrm{BUN}, \mathrm{Cr}$, protein, ASL, lactate, CK, $\mathrm{pH}$, $\mathrm{HCO}_{3}, \mathrm{ABE}$, lactate, or $\mathrm{AaO}_{2}$ resulted in changes closer to baseline values than in animals receiving $\mathrm{HS}$ alone.

\section{Study 2: Effect of hemodynamic support alone or together with PA-mAb during challenge with lethal and edema toxin together Survival}

Twelve animals were challenged with $24 \mathrm{~h}$ infusions of LT and ET together in three weekly experiments (four animals per experiment). Five animals were treated with HS alone, and four and three were treated with $\mathrm{HS}$ combined with raxi administered at 0 or $6 \mathrm{~h}$, respectively (Figure 6A). While all animals receiving $\mathrm{HS}$ alone died with a median survival time (range) of $71.5 \mathrm{~h}$ (65 to $93 \mathrm{~h}$ ), all animals receiving $\mathrm{HS}$ with raxi at either 0 or $6 \mathrm{~h}$ survived for $96 \mathrm{~h}$ (Figure 6A and B). Since these effects on survival were very similar to those observed with $\mathrm{HS}$ with raxi treatment during challenge with ET or LT alone (see above for ET and reference 21 for LT), further experiments were not conducted and data from animals receiving raxi at the two treatment times were combined in survival and other data analysis. Compared to HS alone, animals receiving HS with raxi at 0 or $6 \mathrm{~h}(\mathrm{HS}+\mathrm{mAbT} 0 / \mathrm{T} 6)$ had significantly improved survival $(p=0.01)$.

\section{Other laboratory data}

Due to longer survival with HS alone in Study 2, other laboratory data were examined over the entire $96 \mathrm{~h}$ observation period. Compared to HS alone, HS + mAbT0/T6 significantly increased fluid (urine) output at 48 and $96 \mathrm{~h}$ and net negative fluid balance at $48 \mathrm{~h}$, decreased norepinephrine requirements at 54 to $90 \mathrm{~h}$ (except $78 \mathrm{~h}$ ), increased MAP at 72 and $84 \mathrm{~h}$ and shock index score at 54 and 66 to $90 \mathrm{~h}$ (except $78 \mathrm{~h}$ ) (Figure 6C to H), decreased $\mathrm{HR}$ at 54 to $78 \mathrm{~h}$, and increased CVP at 60 to 72 and $90 \mathrm{~h}(p \leq 0.05)$ (Figure 6C to H, HR and CVP data not shown). Compared to HS alone, HS + mAbT0/T6 also increased $\mathrm{Cl}^{-}$at 6,12 , and $24 \mathrm{~h}$ and $\mathrm{ABE}$ and $\mathrm{HCO}^{-}$at 56, 64, and $88 \mathrm{~h}$ and decreased $\mathrm{AaO}_{2}$ at 48,56 , and $64 \mathrm{~h}$ and PT at $72 \mathrm{~h}(p \leq 0.05$, data not shown). As shown in Figures 6, the effects of HS + mAbT0 and HS + mAbT6 on norepinephrine requirements, MAP, and Shock Index resulted in changes closer to baseline values than in animals receiving $\mathrm{HS}$ alone. Such changes were also the case for $\mathrm{ABE}, \mathrm{HCO}^{-}, \mathrm{AaO}_{2}$, and PT (not shown).

\section{Discussion}

In summary, without any treatment in Study 1, $24 \mathrm{~h}$ ET challenge produced 100\% lethality. Treatment with HS alone produced smaller decreases in blood pressure, but did not improve survival from ET challenge. However, HS combined with raxi at either 0 or $6 \mathrm{~h}$ but not at $12 \mathrm{~h}$, improved survival significantly compared to HS alone. Similarly in Study 2, with LT and ET challenge together, HS combined with raxi at 0 or $6 \mathrm{~h}$ increased survival significantly. 


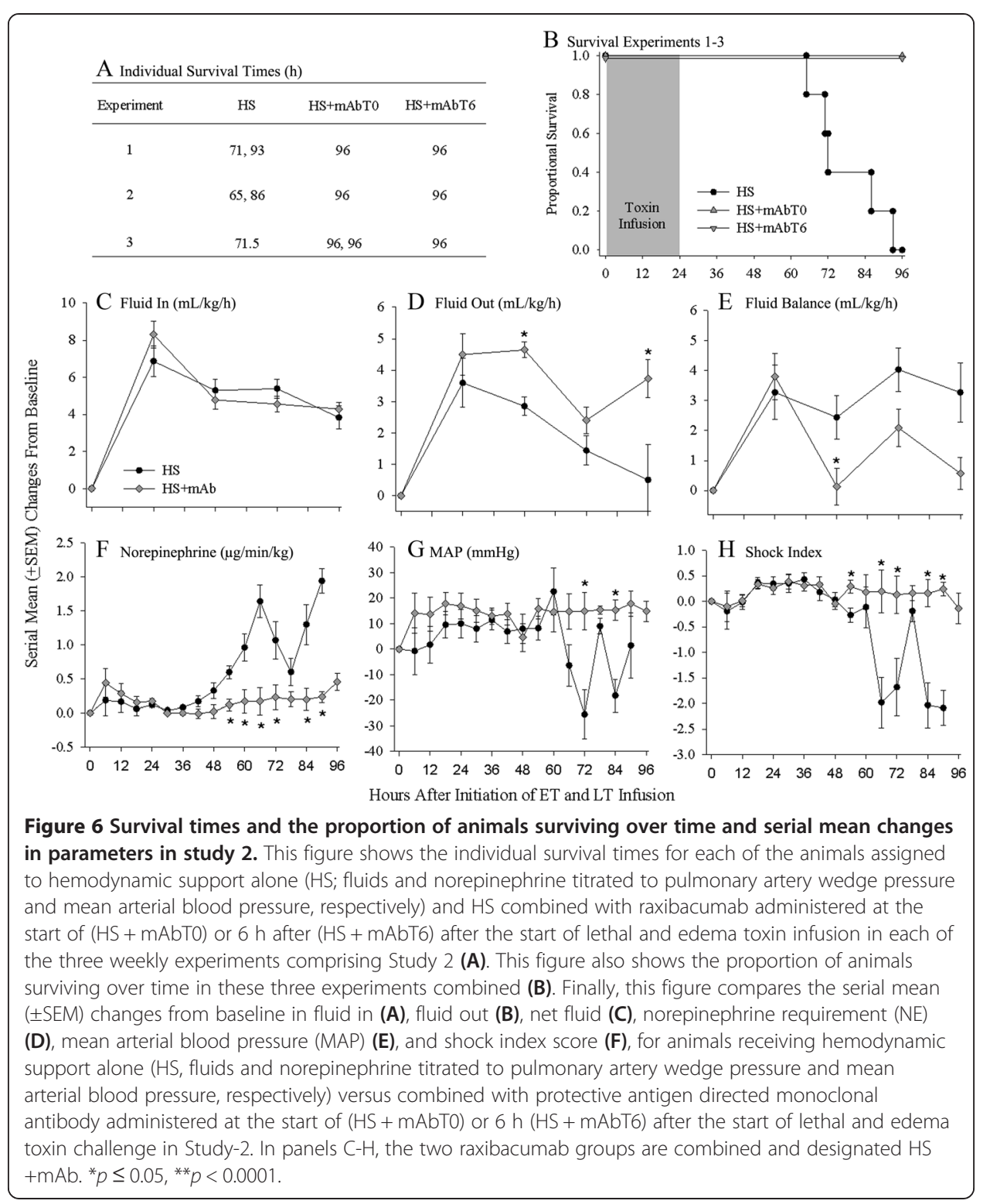

Unlike our prior study where HS improved survival from a lethal LT challenge, HS alone did not improve survival in Study 1 from a similarly lethal ET challenge. Several reasons could account for this difference [21]. First, while lethality with ET was evident before challenge was completed $(<24 \mathrm{~h})$, with LT the first death didn't occur until $24 \mathrm{~h}$ after challenge. Thus, the rapidity of lethality with ET may have negated any beneficial survival effect with HS. Second, in a rat aortic ring model, treatment with lethal concentrations of ET but not LT inhibited the contractile response of rings to phenylephrine [27]. In this canine model, ET may have similarly directly inhibited the beneficial vasopressor effects of norepinephrine. Finally, treating shock from ET challenge with HS alone produced hypoxemia. Although ET has generally not produced gas exchange abnormalities in animal models, fluids in HS may have aggravated ETs edema producing actions. Such an effect could have worsened oxygenation and negated benefit with HS. Previously, HS did not worsen oxygenation during LT challenge [18,21]. 
In contrast to HS alone during ET challenge, HS with raxi administered at 0 or $6 \mathrm{~h}$ significantly increased survival. This survival benefit was associated with increased urine output and net negative fluid balance, reduced vasopressor requirements, and improved blood pressure, shock index score, oxygenation, and organ function (i.e., reduced BUN, Cr, and AST). Furthermore, HS with raxi at the start of ET challenge reduced fluid intake at $24 \mathrm{~h}$, while increasing CVP and SVR. The basis for these effects of HS combined with raxi is likely related to evidence that ET contributes to shock via at least two mechanisms. First, ET weakens the adherens junctions connecting endothelial cells and promotes extravasation of fluid and solute [28-30]. Inhibition of ET and improved endothelial barrier function would provide a basis for the decreased fluid requirement and net negative fluid balance, increased CVP, and improved oxygenation noted with HS and raxi compared to HS alone. Secondly, ET may also cause direct arterial relaxation and inhibit arterial contractile responses to catecholamines [31]. Inhibition of these ET effects provides a basis for the reduced norepinephrine requirements and increased MAP, shock index, and SVR noted with HS and raxi compared to HS alone.

Although HS with raxi administered at $12 \mathrm{~h}$ after starting ET challenge was associated with a small increase in survival, this was not significant. Thus, in contrast to HS with raxi at $6 \mathrm{~h}$, the rapidity of ETs lethal effects may have limited benefit with delayed treatment at $12 \mathrm{~h}$. By contrast, with LT challenge previously in which lethality was not evident until $48 \mathrm{~h}$, treatment with $\mathrm{HS}$ and raxi as late as $12 \mathrm{~h}$ did significantly improve survival [21]. Notably though, in the present study with ET, HS with raxi at $12 \mathrm{~h}$ did produce small increases in blood pressure, reductions in AST, and improved oxygenation.

It is possible that even without HS; raxi might have been beneficial with ET in Study 1. However, in a previous LT challenge study using this same model, raxi lacked any benefit when administered alone after $0 \mathrm{~h}$ but was beneficial for up to $12 \mathrm{~h}$ when combined with HS [21]. That finding suggested that HS augmented the effects of raxi, possibly by promoting its tissue distribution. Based on these prior results and because patients with $B$. anthracis shock would typically receive hemodynamic support, we did not test raxi alone in the present study.

In Study 2, HS combined with raxi at 0 or $6 \mathrm{~h}$ was also beneficial with LT and ET together, improving urine output and net negative fluid balance and reducing norepinephrine requirements while increasing MAP, shock index score, and survival. Although the number of animals studied was relatively small, the results of Study 2 were very similar to those observed with HS and raxi with either lethal ET challenge in Study 1 or with lethal LT challenge in our prior study [21]. From an animal care and usage standpoint, additional experiments were not appropriate. However, the findings from these three studies together (Studies 1 and 2 here, and a prior LT alone study) provide evidence that agents inhibiting LT and ET may be beneficial when added to conventional hemodynamic support for shock caused by these toxins during B. anthracis infection. Such benefit may be twofold, inhibiting organ injury related directly to the toxins and lowering adverse effects of conventional treatments (e.g., fluid overload or vasopressor-induced ischemic injury).

This study has limitations. First, other pathogenic mediators, such as bacterial cell wall and non-toxin proteases, likely contribute to shock with B. anthracis infection [4]. Whether hemodynamic support and raxi would have additive benefit during shock 
related to these other pathogenic mediators is unclear. Second, hemodynamic support in the present study was restricted to fluid and norepinephrine administration. Other vasopressors or inotropes such as phenylephrine, vasopressin, or dobutamine might also have beneficial effects in combination with raxi or other PA directed agents.

\section{Conclusion}

In conclusion, both LT and ET are thought to contribute to shock and organ injury during severe B. anthracis infection. Our findings in this canine model suggest that inhibition of these toxins with PA directed monoclonal antibodies such as raxi likely adds to the benefit of conventional treatments.

\section{Additional file}

Additional file 1: Figure S1. This figure shows the time lines of experimental interventions, measurements, and treatments for Study 1 (A) and Study 2 (B). As outlined in 'Methods', in Study 1 at the initiation of $24 \mathrm{~h}$ edema toxin infusion, animals were randomized to receive hemodynamic support alone, hemodynamic support in combination with protective antigen directed monoclonal antibody (PA-mAb) administered at the time of $(0 \mathrm{~h})$ or 6 or $12 \mathrm{~h}$ after starting toxin infusion, or no treatment. Hemodynamic support included a single bolus of $20 \mathrm{~mL} / \mathrm{kg}$ of normal saline if the pulmonary artery occlusion pressure (PAOP, checked every $2 \mathrm{~h}$ for the first $8 \mathrm{~h}$ and every $4 \mathrm{~h}$ thereafter) was $<10 \mathrm{mmHg}$. Also, if at any time mean arterial blood pressure (MAP) decreased to $<80 \mathrm{mmHg}$ for $>5 \mathrm{~min}$, a norepinephrine infusion was initiated at $0.2 \mu \mathrm{g} / \mathrm{kg} / \mathrm{min}$ and, if necessary, increased in a stepwise fashion every 5 min to 0.6 to 1 or a maximum of $2 \mu \mathrm{g} / \mathrm{kg} / \mathrm{min}$. Norepinephrine was titrated down in a step-wise fashion if MAP was greater than $100 \mathrm{mmHg}$ for $>5 \mathrm{~min}$. Other abbreviations: HR, heart rate; CVP, central venous pressure; LVEF, left ventricular ejection fraction (measured with echocardiography); CBC, complete blood count; $A B G$, arterial blood gas. In Study 2, animals were challenged with lethal toxin and edema toxin in combination and were randomized to treatment with hemodynamic support alone or hemodynamic support combined with PA-mAb administered at the time of or $6 \mathrm{~h}$ after the start of toxin. Other measurements and treatments were similar to Study 1.

\section{Competing interests}

Recombinant anthrax toxins and PA-monoclonal antibody were provided by Human Genome Sciences, Rockville, MD. The authors declare that they have no competing interests.

\section{Author Contributions}

KER, XC, SBS, and PQE contributed to the study design, performed experimental research, compiled data, and drafted/revised the manuscript. JS performed statistical data analysis. YF, YL, JS, AVB, MH, MM, and SHL contributed to manuscript preparation. All authors read and approved the final manuscript.

\section{Acknowledgements}

This research was supported by the Intramural Research Program of the National Institutes of Health including the National Heart, Lung, and Blood Institute, National Institute of Allergy and Infectious Diseases, and the Clinical Center

\section{Funding}

This work was supported by the National Institutes of Health Intramural Program and a Trans- National Institutes of Health/Food and Drug Administration Medical Countermeasures initiative (MCMi) grant (IAA\#224-14-8015).

Data from this study were presented in abstract form at the ATS International meetings in Philadelphia, PA in May 2013 and San Diego, CA in May 2014; and at the FDA MCMi Regulatory Science Symposium in Silver Spring, MD in May 2013 and 2014. (Am. J. Respir. Crit. Care Med., May 2013; 187: A3055; Am. J. Respir. Crit. Care Med., May 2014; 189: A113)

\section{Author details}

${ }^{1}$ Critical Care Medicine Department, Clinical Center, National Institutes of Health, Bldg 10, Rm 2C145, Bethesda, MD 20892, USA. ${ }^{2}$ National Heart, Lung and Blood Institute, National Institutes of Health, Bethesda, MD, USA. ${ }^{3}$ National Institute of Allergy and Infectious Disease, National Institutes of Health, Bethesda, MD, USA.

Received: 25 November 2014 Accepted: 4 February 2015

Published online: 28 February 2015

\section{References}

1. Jernigan JA, Stephens DS, Ashford DA, Omenaca C, Topiel MS, Galbraith M, Tapper M, Fisk TL, Zaki S, Popovic T, Meyer RF, Quinn CP, Harper SA, Fridkin SK, Sejvar JJ, Shepard CW, McConnell M, Guarner J, Shieh WJ, Malecki JM, Gerberding JL, Hughes JM, Perkins BA (2001) Bioterrorism-related inhalational anthrax: the first 10 cases reported in the United States. Emerg Infect Dis 7:933-944 
2. (2011) An Outbreak of Anthrax Among Drug Users in Scotland. http://www.documents.hps.scot.nhs.uk/giz/ anthrax-outbreak/anthrax-outbreak-report-2011-12.pdf

3. Booth MG, Hood J, Brooks TJ, Hart A (2010) Anthrax infection in drug users. Lancet 375:1345-1346

4. Remy KE, Qiu P, Li Y, Cui X, Eichacker PQ (2013) B. anthracis associated cardiovascular dysfunction and shock: the potential contribution of both non-toxin and toxin components. BMC Med 11:217

5. Stevenson EK, Rubenstein AR, Radin GT, Wiener RS, Walkey AJ (2014) Two decades of mortality trends among patients with severe sepsis: a comparative meta-analysis*. Crit Care Med 42:625-631

6. Angus DC, van der Poll T (2013) Severe sepsis and septic shock. N Engl J Med 369:840-851

7. Angus DC, Linde-Zwirble WT, Lidicker J, Clermont G, Carcillo J, Pinsky MR (2001) Epidemiology of severe sepsis in the United States: Analysis of incidence, outcome, and associated costs of care. Crit Care Med 29:1303-1310

8. Kumar G, Kumar N, Taneja A, Kaleekal T, Tarima S, McGinley E, Jimenez E, Mohan A, Khan RA, Whittle J, Jacobs E, Nanchal R, Milwaukee Initiative in Critical Care Outcomes Research Group of I (2011) Nationwide trends of severe sepsis in the 21st century (2000-2007). Chest 140:1223-1231

9. Smith H, Keppie J, Stanley JL, Harris-Smith PW (1955) The chemical basis of the virulence of Bacillus anthracis. IV. Secondary shock as the major factor in death of guinea-pigs from anthrax. Br J Exp Pathol 36:323-335

10. Stanley JL, Smith H (1961) Purification of factor I and recognition of a third factor of the anthrax toxin. J Gen Microbiol 26:49-63

11. Lowe DE, Glomski IJ (2012) Cellular and physiological effects of anthrax exotoxin and its relevance to disease. Front Cell Infect Microbiol 2:76

12. Sweeney DA, Hicks CW, Cui X, Li Y, Eichacker PQ (2011) Anthrax infection. Am J Respir Crit Care Med 184:1333-1341

13. Levinsohn JL, Newman ZL, Hellmich KA, Fattah R, Getz MA, Liu S, Sastalla I, Leppla SH, Moayeri M (2012) Anthrax lethal factor cleavage of NIrp1 is required for activation of the inflammasome. PLoS Pathog 8:e1002638

14. Leppla SH (1982) Anthrax toxin edema factor: a bacterial adenylate cyclase that increases cyclic AMP concentrations of eukaryotic cells. Proc Natl Acad Sci U S A 79:3162-3166

15. Hoover DL, Friedlander AM, Rogers LC, Yoon IK, Warren RL, Cross AS (1994) Anthrax edema toxin differentially regulates lipopolysaccharide-induced monocyte production of tumor necrosis factor alpha and interleukin-6 by increasing intracellular cyclic AMP. Infect Immun 62:4432-4439

16. Laine $E$, Martinez L, Blondel A, Malliavin TE (2010) Activation of the edema factor of Bacillus anthracis by calmodulin: Evidence of an interplay between the EF-calmodulin interaction and calcium binding. Biophys $J$ 99:2264-2272

17. Gottle M, Dove S, Kees F, Schlossmann J, Geduhn J, Konig B, Shen Y, Tang WJ, Kaever V, Seifert R (2010) Cytidylyl and uridylyl cyclase activity of bacillus anthracis edema factor and Bordetella pertussis CyaA. Biochemistry 49:5494-5503

18. Sweeney DA, Cui X, Solomon SB, Vitberg DA, Migone TS, Scher D, Danner RL, Natanson C, Subramanian GM, Eichacker PQ (2010) Anthrax lethal and edema toxins produce different patterns of cardiovascular and renal dysfunction and synergistically decrease survival in canines. J Infect Dis 202:1885-1896

19. Cui X, Li Y, Li X, Laird MW, Subramanian M, Moayeri M, Leppla SH, Fitz Y, Su J, Sherer K, Eichacker PQ (2007) Bacillus anthracis edema and lethal toxin have different hemodynamic effects but function together to worsen shock and outcome in a rat model. J Infect Dis 195:572-580

20. Molin FD, Fasanella A, Simonato M, Garofolo G, Montecucco C, Tonello F (2008) Ratio of lethal and edema factors in rabbit systemic anthrax. Toxicon 52:824-828

21. Barochia AV, Cui X, Sun J, Li Y, Solomon SB, Migone TS, Subramanian GM, Bolmer SD, Eichacker PQ (2012) Protective antigen antibody augments hemodynamic support in anthrax lethal toxin shock in canines. J Infect Dis 205:818-829

22. Migone TS, Subramanian GM, Zhong J, Healey LM, Corey A, Devalaraja M, Lo L, Ullrich S, Zimmerman J, Chen A, Lewis M, Meister G, Gillum K, Sanford D, Mott J, Bolmer SD (2009) Raxibacumab for the treatment of inhalational anthrax. N Engl J Med 361:135-144

23. Young JA, Collier RJ (2007) Anthrax toxin: Receptor binding, internalization, pore formation, and translocation. Annu Rev Biochem 76:243-265

24. Ascenzi P, Visca P, Ippolito G, Spallarossa A, Bolognesi M, Montecucco C (2002) Anthrax toxin: a tripartite lethal combination. FEBS Lett 531:384-388

25. Maynard JA, Maassen CB, Leppla SH, Brasky K, Patterson JL, Iverson BL, Georgiou G (2002) Protection against anthrax toxin by recombinant antibody fragments correlates with antigen affinity. Nat Biotechnol 20:597-601

26. Altaweel L, Sweeney D, Cui X, Barochia A, Natanson C, Eichacker PQ (2009) Growing insights into the potential benefits and risks of activated protein $\mathrm{C}$ administration in sepsis: a review of preclinical and clinical studies. Biologics Targets Ther 3:391-406

27. Minneci PC, Deans KJ, Hansen B, Parent C, Romines C, Gonzales DA, Ying SX, Munson P, Suffredini AF, Feng J, Solomon MA, Banks SM, Kern SJ, Danner RL, Eichacker PQ, Natanson C, Solomon SB (2007) A canine model of septic shock: balancing animal welfare and scientific relevance. Am J Physiol Heart Circ Physiol 293:H2487-H2500

28. Li Y, Cui X, Solomon SB, Remy K, Fitz Y, Eichacker PQ, (2013) B. anthracis edema toxin increases CAMP levels and inhibits phenylephrine stimulated contraction in a rat aortic ring model. Am J Physiol Heart Circ Physiol.

29. Guichard A, McGillivray SM, Cruz-Moreno B, van Sorge NM, Nizet V, Bier E (2010) Anthrax toxins cooperatively inhibit endocytic recycling by the Rab11/Sec15 exocyst. Nature 467:854-858

30. Maddugoda MP, Stefani C, Gonzalez-Rodriguez D, Saarikangas J, Torrino S, Janel S, Munro P, Doye A, Prodon F, Aurrand-Lions M, Goossens PL, Lafont F, Bassereau P, Lappalainen P, Brochard F, Lemichez E (2011) CAMP signaling by anthrax edema toxin induces transendothelial cell tunnels, which are resealed by MIM via Arp2/3-driven actin polymerization. Cell Host Microbe 10:464-474

31. Ebrahimi CM, Sheen TR, Renken CW, Gottlieb RA, Doran KS (2011) Contribution of lethal toxin and edema toxin to the pathogenesis of anthrax meningitis. Infect Immun 79:2510-2518 